\title{
ATCI vs. BRICS: consecuencias sobre la geopolítica y las relaciones internacionales del siglo XXI
}

\author{
Santiago Armesilla Conde \\ Departamento de Economía, Desarrollo y Medio Ambiente \\ Euro-Mediterranean University Institute (EMUI) \\ sjarmesi@ucm.es
}

Recibido: 08-10-2014

Aceptado: 07-03-2016

\begin{abstract}
Resumen
La ATCI es una propuesta en negociaciones entre la UE y EEUU para crear el más grande área de libre comercio internacional por extensión, población y volumen de intercambio comercial, de todas las existentes. A nuestro juicio, la ATCI sería la respuesta geoeconómica a los BRICS como espacio geopolítico, comercial y de cooperación en otros ámbitos como el militar en tanto que la ATCI reproduce a escala comercial la alianza político-militar ya existente entre buena parte de la UE y EEUU por la OTAN. En este artículo trataremos de exponer por qué la posible rivalidad ATCI vs. BRICS reproduciría en el siglo XXI los esquemas de "Guerra Fría" heredados del siglo XX, que a su vez reproducían los enfrentamientos geopolíticos derivados de la teoría del área pivote de Haltford McKinder y la tradicional contraposición entre imperialismos talasocráticos (gobierno sobre los mares y océanos) e imperialismos telurocráticos (gobierno sobre una extensísima porción de tierra emergida). Asímismo, trataremos de mostrar por qué a nivel de dialéctica de Estados aquellas sociedades políticas más pobladas, más extensas territorialmente y con mayor cantidad de recursos serán las que tengan mayor capacidad para imponer un determinado modelo de relaciones internacionales y de hegemonía geopolítica a escala universal atendiendo a este viable enfrentamiento ATCI, más ATCE, vs. BRICS.
\end{abstract}

Palabras clave: ATCI; BRICS; Unión Europea; OTAN; imperialismo.

\section{TTIP vs. BRICS: Consequences on Geopolitics and Internacional Relations of the XXIst. Century}

\begin{abstract}
The TTIP is a proposal on negotiations between the EU and the USA in order to create the largest free international trade area by extension, population and volume of trade of all existing ones. In our view, TTIP would be the geoeconomic answer to BRICS (Brazil, Russia, India, China and South Africa), as a comercial, geopolitical and cooperation space in other areas such as the military, in both that TTIP reproduce on a commercial scale the political and military alliance already existing between good part of the EU and USA by the NATO. In this paper we will try to explain why the possible rivalry between TTIP and BRICS would reproduce in the XXIst. Century the schemes of "Cold War" inherited from XXth. Century, that in turn reproduced the geopolitical confrontations arising from the theory of Haltford McKinder pivot area and the traditional opposition between thalassocratic imperialisms (government on the seas and oceans) and tellurocratic imperialisms (government on an enormous portion of emerged land). Likewise, we will try to show why, at a dialectic of States level, the most populated, territorially extensive and with greater amount of resources political societies will be those that have the greatest ability to impose a particular model of international relations and its geopolitical hegemony on a universal scale in response to this viable confrontation between TTIP, plus TTP, vs. BRICS.
\end{abstract}

Key words: TTIP; BRICS; European Union; NATO; imperialism. 


\section{Referencia normalizada}

Armesilla Conde, S. (2016): "ATCI vs. BRICS: consecuencias sobre la geopolítica y las relaciones internacionales del siglo XXI", Política y Sociedad, 53 (2), pp. 621-637.

Sumario: 1. Qué es la ATCI. 2. Qué son los BRICS. 3. Plataformas continentales, dialéctica de Estados y dialéctica de Imperios universales a través de la ATCI y los BRICS. 4. Conclusiones. Dialécticas políticas y determinismo causal histórico. 5. Abreviaturas. 6. Bibliografía.

\section{Qué es la ATCI}

Para poder profundizar mejor en las conexiones entre la ATCI y otras instancias supranacionales de las cuales heredaría en gran medida su conformación histórica futura, su relación dialéctica con los BRICS y lo que estos heredan también, es preciso primero tratar de explicar en qué consiste la ATCI. Nuestra introducción a la ATCI será, en principio, histórico-económica y geopolítica (Alcázar y Montejo, 2014), por lo que recurriremos en un inicio a fuentes oficiales de la Unión Europea para explicar los contenidos de este gran tratado económico-político en construcción.

Según la Comisión Europea en su representación para España, la ATCI tiene como principal fundamento y misión la eliminación de las barreras comerciales entre los EEUU y la UE, particularmente los aranceles, considerados por esta Comisión como innecesarios y restrictivos a las inversiones (Comisión Europea -representación en España-, 2014). Una de las vías para esta eliminación de aranceles sería la simplificación de la compra y la venta de mercancías de toda clase en este gran espacio geoeconómico. Más empleo, más crecimiento económico y menores precios son los objetivos buscados y vendidos como características esenciales de la ATCI. El hecho de que estas premisas aparezcan en la web oficial de la Comisión Europea en su representación para España significa claramente a nuestro juicio que tanto el Gobierno de España como el resto de Gobiernos de los Estados de la UE, así como las instituciones gubernamentales y diplomáticas de la UE en Bruselas y Estrasburgo están ya totalmente alineadas con las premisas básicas de la construcción de la ATCI, esto es, con la aquiescencia y guía de Washington (Alcázar y Montejo, 2014), previendo un crecimiento económico considerable para la UE mayor que para los EEUU. Las previsiones son de 126.000 millones de euros y 95.000 millones respectivamente, un alza del PIB español en más del 6,5\% y la generación de cerca de 143.000 nuevos trabajos solo en España, sin especificar en qué condiciones y en qué puestos de trabajo, aunque se llega a decir que el ingreso medio de una familia de cuatro miembros de la UE vería un incremento de hasta 545 euros anuales (Center for Economic Policy Research, 2013). También se prevé un aumento inclusive del PIB mundial de hasta 100.000 millones de euros (Alcázar y Montejo, 2014: 4).

La ATCI, como toda alianza geopolítica y geoeconómica, necesitaría un leit motiv ideológico, un ortograma o molde activo capaz de formalizar los materiales dados en toda conformación (García Sierra, 2000: 297), materiales ya conformados previamente como son las instituciones económico-políticas estadounidenses y europeístas, así como los Estados mismos que participarían en la construcción de este gran acuerdo transatlático. El ortograma de la ATCI queda explicitado así: 
"Los Estados Unidos y la Unión Europea (UE) comparten los valores fundamentales de la libertad, la democracia, los Derechos Humanos y el respeto a la Ley. Trabajamos juntos para impulsar la seguridad energética, abordar el cambio climático global e impulsar el desarrollo económico. Cooperamos en materia de lucha contra el terrorismo y cuestiones de seguridad. Una sólida economía transatlántica refuerza nuestra capacidad para afrontar los retos de alcance mundial y promover el desarrollo global y la prosperidad" (Bureau of Public Affairs, 2013: 1).

Esta línea geoeconómico-comercial ya fue indicada por el propio actual presidente estadounidense, Barack Obama, en su Discurso sobre el estado de la Unión (2013), donde por primera vez afirmó la necesidad de un gran acuerdo comercial transatlántico entre la UE y EEUU. Acuerdo que reforzaría una ya fluida política económica entre ambas orillas del Atlántico Norte, que solo en el año 2013 generó unos 1,6 billones de euros en la balanza comercial de la UE en su comercio con Estados Unidos, generando estos unos 1,35 billones de euros en su propia balanza comercial, en un claro signo de crecimiento de las ganancias por el comercio que el año anterior, 2012, alcanzó el billón de euros en ambas latitudes noratlánticas (Alcázar y Montejo, 2014: 3). Esta relación comercial masiva es seguida desde antes del 2011 por ambas unidades geopolíticas. En 2011, entre la UE y EEUU hubo un intercambio bilateral total de mercancías que ascendió a un valor de más de 455.000 millones de euros, con un saldo positivo para la UE de más de 72.000 millones de euros (Alcázar y Montejo, 2014: 6). Los tipos de mercancías más intercambiados por la UE y EEUU son, por este orden, maquinaria, servicios de transporte y productos químicos, elevándose en ese mismo año el valor intercambiado en servicios hasta los 282.300 millones de euros, lo que coloca a EEUU como el principal socio en la provisión de servicios a todos los Estados de la UE, llegando a oscilar las cifras de intercambio inversor entre empresas entre los 120.000 y los 150.000 millones de euros en el año 2011. La cifra de intercambios comerciales diarios entre la UE y EEUU, a día de hoy, alcanza una media de 2000 millones de euros (Alcázar y Montejo, 2014: 6-7).

La conjunción entre democracia, libertad (de expresión, asociación y reunión), Derechos Humanos y legalidad, es indisociable, en los principios ortogramáticos de la ATCI, de la libertad de comercio. Esta libertad total de comercio se asocia a nulas barreras aduaneras y a un estado prácticamente perenne de paz internacional donde los Estados ejerzan de meros gendarmes de las actividades mercantiles de sus clases burguesas, dando una clara lectura liberal a la idea de "paz perpetua" kantiana (Kant [1795] 1983) en el marco de la llamada "globalización” (García Matías, 2014).

"Juntos, EEUU y la UE pueden impulsar la liberalización multilateral en un mundo globalizado. En el G-8, el G-20, la Organización Mundial del Comercio y la Organización para la Cooperación y el Desarrollo Económico, EEUU y la UE trabajan juntos para promover un entorno de comercio e inversión abierto, transparente y no discriminatorio en todo el Mundo" (Bureau of Public Affairs, 2013: 2).

Hay que destacar que el G-8 ha sido temporalmente reestructurado como G-7 tras la exclusión temporal de Rusia por la crisis de Crimea. El G-7 resultante está integrado por 
Estados Unidos y el núcleo duro económico-político e industrial de la UE -Alemania, Reino Unido, Francia e Italia- más Canadá y Japón. Esta reagrupación geopolítica coincide, además, con lo que en otros escritos hemos denominado choque entre las plataformas continentales anglosajona-europea y ruso-eslava (Armesilla, 2014a; Armesilla, 2014b). Se trataría de un choque geopolítico derivado de la recuperación de presencia económica, militar y geopolítica por parte de Rusia en el siglo XXI, tras la década de 1990 y el gobierno de Boris Yeltsin, mandatario que heredó una Rusia desestructurada tras la caída de la Unión Soviética en 1991 y de todo su bloque imperial, y que solo con la llegada de Vladimir Putin al poder en 2000 empezó a recuperar su tradicional presencia en las relaciones internacionales a escala universal (Todd, 2003). Además el G-20, como foro de cooperación al desarrollo económico y social, es una organización supraestatal donde confluyen no solo los futuros Estados miembros de la ATCI, es decir, EEUU más UE, además de Canadá y México como posibles integrantes también de este acuerdo transatlántico. En el G-20 también se encuentran los miembros de los BRICS, a los cuales podrían unirse en el futuro Argentina, Corea del Sur y México, nación política de esencial importancia geoestratégica para unos y otros. Por su parte, la OCDE cuenta con 34 Estados miembros, prácticamente toda la UE y EEUU más Suiza y Noruega, Estados europeos que también podrían ser incluidos en la ATCI. Otros miembros de la OCDE son Turquía, Japón, Corea del Sur, Australia y Chile.

Las exigencias de Política Económica que la firma del ATCI conllevaría para poder acrecentar y mejorar los datos ya señalados serían los siguientes (Center for Economic Policy Research, 2013):

a) Eliminación o reducción de impuestos y aranceles para el comercio de mercancías y líquidos activos a la inversión.

b) Compatibilización reforzada de los estándares de regulación comercial.

c) Fortalecimiento de los acuerdos de cooperación económica en todos los ámbitos entre los Estados miembro de la ATCI.

Tras la aprobación de la ATCI, todas las obligaciones en comercio bilateral habrían de ser eliminadas, especialmente los aranceles, así como otras tasas que serían eliminadas progresivamente. Se tendrían que superar los niveles de liberalización económica alcanzados hasta la fecha en materia de intercambio internacional de servicios, de inversiones (sin dejar de garantizar la protección jurídica de los inversores) y de oportunidades de negocio tanto público como privado. La creación de un espacio regulatorio compartido entre la UE y EEUU exigiría, además, la reducción más drástica posible de las barreras no arancelarias y los costes asociados de las diferencias regulatorias.

La cooperación en materia comercial continúa una cooperación anterior que, en realidad, tiene décadas de existencia. En la coyuntura actual de crisis económica causada por la sobreproducción en la esfera de la oferta sobre una demanda insuficiente (Guerrero, 1989), los actuales problemas de cooperación tratan de mitigarse mediante la expansión crediticia masiva por parte de EEUU y los Estados miembros de la UE (Schiff, 2014). La actual cooperación entre EEUU y la UE debería ser sobrepasada y profundizada ante la amenaza que supone, para ellos, el crecimiento económico, político y militar de Rusia y, sobre todo, de China. 
En realidad, el ATCI sería la profundización de un mercado ya generado desde hace siglos, prácticamente desde la llegada de los primeros europeos a América del Norte en el siglo XVII. Este mercado tiene su punto de inflexión a comienzos del siglo XX con el final de la Primera Guerra Mundial en 1918, convertida ya EEUU en la primera potencia económica, militar e industrial del Mundo. Hegemonía que fue posible tras una planificación económica bélica sin precedentes en la Historia de cara a su entrada en la Segunda Guerra Mundial, ayudada por la destrucción de fuerzas productivas producida en otras naciones potentes que también entraron en ambas guerras mundiales. EEUU consiguió acrecentar su poderío económico e industrial hasta niveles antes inimaginables en la Historia de las grandes potencias económicas contemporáneas (Beneyto, Martín de la Guardia y Pérez Sánchez, 2005).

Tras el final de la Segunda Guerra Mundial se empiezan a conformar dos grandes bloques políticos, ideológicos, económicos y militares opuestos que parten el Mundo en dos. De un lado, el bloque del COMECON y el Pacto de Varsovia, liderado por la Unión Soviética, y cercano a la República Popular China hasta la guerra que ambos Estados mantuvieron en la frontera manchú que comparten al extremo oriente rusochino en la década de 1960. De otro lado, el bloque que lideran los Estados Unidos. El 4 de abril de 1949 se firma el Tratado del Atlántico Norte. Previamente se firmó en 1948 su precursor, el Tratado de Bruselas, ratificado por el Reino Unido, Francia, Países Bajos, Luxemburgo y Bélgica, por el que se constituye un acuerdo de defensa colectiva frente al bloque soviético. En esta defensa colectiva se integran Estados Unidos, Canadá, Islandia, Dinamarca, Portugal, Noruega, Países Bajos, Bélgica, Luxemburgo, Italia, Reino Unido y Francia. En la sección V de este Tratado se acuerda que un ataque militar dentro del territorio de cualquiera de estos Estados sería tomado como un ataque a todos ellos, aunque ésto no se aplicaría hasta después de los atentados terroristas del World Trade Center del 11 de septiembre de 2001, diez años después del fin de la Guerra Fría. Progresivamente, a la OTAN se fueron adhiriendo otros países como España, Turquía, Grecia y multitud de naciones del fenecido bloque soviético como Albania, Eslovenia, Croacia, Estonia, Letonia, Lituania, Polonia, República Checa, Eslovaquia, Hungría, Rumania y Bulgaria, además de la República Democrática Alemana que, tras reunificarse con la República Federal Alemana en 1990, que entró en la OTAN en 1955, posibilitó que la Alemania reunificada estuviera en la Organización de defensa noratlántica.

Este acuerdo militar transatlántico permitió a Estados Unidos proteger los procesos de integración comercial y mercantil de varios Estados europeos frente al miedo al expansionismo soviético hacia Occidente. Dos años después del Tratado del Atlántico Norte, en 1951, la República Federal Alemana, Francia, Italia, Luxemburgo, Bélgica y los Países Bajos firmaron el Tratado de París, por el que se conforma la CECA. La CECA y la OTAN pusieron las bases para la firma, el 27 de mayo de 1952, del Tratado que inicia la CED, cuyos miembros son los mismos Estados que integran la CECA, aunque la CED no llegó a establecerse del todo, supliendo su vacío la ya existente OTAN en buena medida, hasta hoy día. Posteriormente, el 25 de marzo de 1957, se firmará en Roma un doble tratado en el que se da origen tanto a la EURATOM, siendo Francia la primera potencia atómica de Europa Occidental, protegida por Estados 
Unidos, como a la CEE. Con la progresiva ampliación de estas tres organizaciones supraestatales a más Estados, se llega a la firma en 1985 del Acuerdo de Schengen (ciudad luxemburguesa), por el que se liberalizan los flujos migratorios y de mano de obra dentro de la CEE, y siete años después a la firma del TUE en Maastricht, Países Bajos, afianzando la orientación defensiva común europeísta y también a la unidad en materia federativa y diplomática (Bueno, 1991).

Con la entrada en vigor del TUE en 1992 y del Acuerdo de Schengen en 1995 la CECA, el EURATOM y la CEE se fusionan en la actual UE, siendo otro paso definitivo en su conformación la formación de la ECU en 1979, siendo sustituida por el euro en 1995 entrando en vigor como moneda de curso legal en 2002, previo establecimiento de sus tipos fijos en 1999, en prácticamente todos los Estados de la UE además de Andorra, San Marino, la Ciudad del Vaticano, Mónaco, Montenegro y Kósovo. El euro es hoy día la segunda moneda más negociada del Mundo y la segunda moneda de reserva tras el dólar estadounidense. Con la firma del Tratado de Lisboa en 2007, que aparentemente da personalidad jurídico-política a la UE para firmar tratados internacionales comunitarios con otros Estados, se cierra el proceso de conformación de "Europa" como unidad política homologada a nivel universal.

Toda esta conformación histórica y esta sucesión de Tratados, Acuerdos y alianzas, fue más que tenida en cuenta por el campo soviético prácticamente desde que empezó, pues vieron que era una amenaza a sus intereses geoestratégicos, incluida la expansión internacional de la revolución comunista, cimentada en buena medida en la victoria sobre Alemania en la Segunda Guerra Mundial y su partición en dos Estados distintos bajo control de los vencedores de la guerra. En el periódico soviético Коммунист (El Comunista), se publicaba en su número 9 de 1957 un Informe del Instituto de Economía y Relaciones Internacionales de la Academia de Ciencias de la URSS (1957: 88-102), donde se presentaban 17 tesis sobre la CEE, actual UE, en las cuales se afirmaba lo siguiente:

"El proyecto de la CEE es un proyecto de los EEUU para propiciar que la República Federal de Alemania se haga con la hegemonía y control de la Europa Occidental" (Hallstein y Bräker, 1975: 81-101).

La oposición de la URSS a la unión económica europea auspiciada por los Estados Unidos fue constante hasta su disolución (Martín de la Guardia y Pérez Sánchez, 2005). En 1979, con Adolfo Suárez en la presidencia del Gobierno español, la URSS a través del periódico Pravda señaló en sendos artículos que esperaba que España se mantuviera neutral en lo militar tras el fin de la dictadura franquista y el comienzo de la monarquía parlamentaria y democrática del régimen constitucional de 1978. La URSS estimaba que la entrada de España en la CEE tenía una consideración eminentemente política que arrastraría a España a la integración en el bloque de la OTAN, integración iniciada tras los acuerdos hispanoestadounidenses firmados por Franco y Eisenhower en la década de 1950. La URSS estimaba que los entonces nueve integrantes de la CEE (República Federal de Alemania, Países Bajos, Bélgica, Luxemburgo, Francia, Italia, Reino Unido, Irlanda y Grecia) no iban a estar dispuestos a hacer partícipe a España de 
sus privilegios económicos, pensando que antes de diez años España no tendría pleno reconocimiento del resto de Estados de la CEE (el ingreso de España se produjo en 1986). Incluso se planteó la posibilidad de, a cambio de la neutralidad militar española, cercana al llamado bloque de los "Países no alineados", aquellos que no se integraban ni en la OTAN ni en el Pacto de Varsovia, la URSS prestaría ayuda económica en aquellos sectores en que según ellos más flaqueaba la economía española: metalurgia, construcción naval e industrial textil (López Muñoz, 1979).

Como vemos, la URSS veía a la CEE, posterior UE, como un producto indisoluble de la OTAN, con el peligro que conllevaría para aquella la entrada plena de España en este conglomerado político, económico y militar. La URSS ya temía que Alemania se convirtiese, con la permisividad estadounidense, en la nueva potencia hegemónica europea. Si la estructura político-económico-militar del binomio OTAN-UE, que la URSS vio conformarse progresivamente, se profundizara con la ATCI, conservando las estructuras anteriores para, a partir de ellas, afianzar las relaciones internacionales de los Estados del Atlántico Norte, ¿acaso en la OTAN no se ve a los BRICS como una reedición del Pacto de Varsovia en pleno siglo XXI en un doble sentido, primero el de recomposición de la tradicional esfera imperial rusa en Europa del Este por una parte, y segundo de posible nueva expansión del peligro comunista que ahora representaría la República Popular China? Para responder a esta pregunta es necesario tratar de ver si los mencionados BRICS son una reedición de esas estructuras político-militares y económicas que en el siglo pasado se consolidaron alrededor del liderazgo de Moscú.

\section{Qué son los BRICS}

BRICS son las siglas de Brasil, Rusia, India, China y Suráfrica (O' Neill, 2001), y hacen referencia a los llamados "Estados emergentes" más importantes a nivel internacional (Suráfrica se uniría a los iniciales BRIC en 2011), los cuales asumieron esta nomenclatura en 2008. Salvo Rusia, el resto de BRICS también pertenecen al G5 junto con México, que en dialéctica de Estados (Bueno, 2001) ejercen relaciones diplomáticas de toda clase con los miembros del arriba mencionado G-8. Fue a iniciativa de Rusia, en el marco de la reunión del G-8 en Japón en 2008, que se institucionalizó la organización BRICS, siendo muy fluida hasta hoy día. Todos estos Estados tienen varias cosas en común:

a) Ninguno pertenece a la OCDE, motivo por el cual todavía ni México ni Corea del Sur pertenecen a los BRICS aunque compartan características comunes con ellos. Argentina no está en la OCDE, y por compartir características económicopolíticas con los BRICS fue invitada a la Cumbre de Fortaleza, en Brasil, que los BRICS celebraron en el verano de 2014.

b) Quieren promover un nuevo tipo de relaciones internacionales y económicas en donde, por ejemplo, el Banco Mundial con sede en Washington, capital de los Estados Unidos, se convierta en una institución mediadora en materia económica en el marco de unas nuevas relaciones internacionales multipolares y con una menor diferenciación entre bloques (lease, Europa-Estados Unidos / resto del Mundo). Asímismo, los BRICS abogan por tener un mayor peso en el Fondo 
Monetario Internacional, cuya sede también está en Washington. Una institución cuyo cometido, aparentemente, es mantener la estabilidad y el equilibrio del comercio internacional.

c) Cada uno de los BRICS tiene una enorme extensión territorial, especialmente Rusia, el país más extenso del Planeta. Cada uno tiene, también, una población muy numerosa, sobre todo China y la India, que sobrepasan los mil millones de habitantes cada una, y que junto con Rusia, Suráfrica y Brasil suponen más del $40 \%$ de la población mundial. Todos tienen un crecimiento superior a la media global, especialmente la República Popular China, que junto con el resto de BRICS hace una suma total de valor de unos 135.000 billones de dólares de todo el PIB mundial. Todos tienen, además una "clase media" en proceso expansivo y con alta capacidad de consumo, y una capacidad en recursos naturales y gestión de los mismos que permitiría a los BRICS ser los herederos de la hegemonía económico-política internacional hacia mediados del siglo XXI tras el G-7 (O' Neill, 2001).

d) China y la India podrían convertirse en este siglo XXI en los principales proveedores mundiales de servicios y de bienes tecnológicos, y Rusia y Brasil podrían convertirse asimismo en los principales proveedores de materias primas y de alimentos a escala global, aumentando también su exportación de bienes industriales (Wilson y Purushothaman, 2003).

e) Los BRICS son los Estados que más inversión extranjera directa tienen. Esto hace que las grandes "transnacionales" de Estados integrantes del futuro ATCI sean las que más invierten en países como China e India, donde la industria automovilística ha crecido considerablemente y en donde dichas "transnacionales" podrán producir coches más baratos para adaptarlos al consumo medio de las clases medias de los BRICS, las cuales podrían llegar a tener en 2045 unos ingresos anuales cercanos a los 30.000 dólares estadounidenses (Wilson y Purushothaman, 2003).

f) Los BRICS han podido manejar la crisis económica mundial de 2007, que dura hasta hoy, mejor que el resto de Estados del Mundo.

Aun cuando los BRICS tienen todas estas características comunes, algunos analistas consideran que se trata de una "comunidad fantasma" (Majfud, 2009), sin capacidad de organizarse más allá de la cooperación diplomática y comercial como pueda hacer la UE o incluso la ASEAN. Sin embargo, en este tipo de análisis, excesivamente sesgados a nuestro juicio, no se tiene en cuenta el componente geopolítico e histórico que los BRICS pueden tener, parejo y paralelo, aunque en dirección opuesta, al que tiene la ATCI. Salvo Rusia, el resto de BRICS pertenecen al llamado, desde 2014, G-133, antes conocido desde 1964 como G-77 o "Países no alineados", arriba mencionados. La cooperación en materia geoestratégica de los BRICS y el G-133 frente a las acciones del campo de la futura ATCI es manifiesta, como es el caso del apoyo del programa nuclear iraní, nación miembro del G-133:

"En los últimos años se ha podido apreciar cómo los BRICS han dejado de lado la cuestión económica y saltado a la arena política. Hace poco respaldaron a Irán en 
el desarrollo de su programa nuclear, desafiando abiertamente la política exterior de los EEUU" (Ladines, 2013: 52).

No obstante, no podemos compartir una visión "regionalista" (Ladines, 2013) pareja a la UE respecto de los BRICS, y ni siquiera llegar a pensar que los BRICS podrían, debido a su creciente peso en la economía internacional, convertir al G-133 en una gran región económica mundial. Esto es porque, a pesar de la apariencia de "mutipolaridad" que pueda sostenerse de sus acciones respecto de la UE y de EEUU, cada uno de los BRICS tiene sus propios intereses geoestratégicos. La firma en el 2014 del Tratado que permitirá en el 2015 la configuración de la UEE, integrada por Rusia, Bielorrusia y Kazajistán, con las posibles incorporaciones de Kirguistán y Armenia, no solo acercaría todas estas repúblicas exsoviéticas a las economías BRICS, sino que sobretodo constituye una recuperación por parte de Rusia de su tradicional influencia en su área de influencia geopolítica tradicional, sobre la que Rusia ha ejercido su hegemonía tanto en los tiempos de la Rusia zarista como en los de la Unión de Repúblicas Socialistas Soviéticas, siendo la Federación Rusa actual continuadora de ambas.

\section{Plataformas continentales, dialéctica de Estados y dialéctica de Imperios universales a través de la ATCI y los BRICS}

Por plataforma continental entendemos una configuración o conjunto de relaciones resultado de operaciones humanas a nivel antropológico-institucional (cultural) y político, conformadas en un contexto determinante antropológico-histórico de varios siglos, que conservan una unidad entre sus términos mediante relaciones de continuidad, contigüidad y proximidad a través de las unidades políticas fundamentales de estas plataformas, los Estados. Son los Estados los que conforman estas plataformas, fruto de unidades geopolíticas y geoculturales anteriores como son los Imperios.

Sin negar la pluralidad institucional (Bueno, 2005: 3-52) dentro de cada plataforma continental, se da en ellas una unidad objetivable, una identidad configuracional histórica única y una igualdad simétrica, transitiva y reflexiva respecto de otras plataformas continentales, igualdad que no anega sus diferencias, pero objetivable a través de diversas características. Asimismo, estas plataformas continentales son sistemas de relaciones políticas que hacen referencia, sin reducirlas solo a ellas, a instituciones que las limitan a nivel cultural, lingüístico, religioso, geográfico e histórico. Instituciones que son todas ellas multiplicidades finitas y heterogéneas, que poseen una dimensión de carácter distributivo desde una alternatividad de tipo lógico y cuyas partes heterogéneas, formadas a su vez por otras partes heterogéneas también, determinan su complejidad. Las plataformas continentales son, desde nuestro enfoque, totalidades mixtas. Una totalidad mixta sería el resultado dialéctico de la conjunción de otros dos tipos de elementos típicos de totalidades que definiríamos como atributivas y distributivas. Las totalidades atributivas solo constituirían un todo estando unidas, pero sin necesidad de ser inseparables. Por su parte, las totalidades distributivas son aquellas cuyas partes son independientes entre sí en el momento de su participación en el todo, siendo estas partes homogéneas entre sí. Las totalidades mixtas (Bueno, 1992: 
1401-1441) serían aquellas en las que el conjunto de partes propias de las totalidades distributivas mantienen relaciones de contigüidad y contacto al mismo tiempo que las mantienen de discontinuidad, pues tanto las instituciones antropológicas básicas de cada plataforma continental (idioma, tradiciones y costumbres, relaciones de parentesco, religión, etc.) como los conjuntos complejos de instituciones en que se entretejen estas en cada plataforma continental (los Estados), mantienen claras relaciones mixtas entre sí, teniendo un reflejo político inmediato aún tratándose, en principio, solo de relaciones internacionales de tipo comercial o diplomático.

Estas plataformas continentales sufren, por analogía, variaciones históricas (antropológico-políticas) similares a las que sufren las placas tectónicas en geología (Armesilla, 2014b). Debido a la convección política que produce el calor de los cambios políticos históricos, dada a través de la dialéctica de clases y de Estados (Bueno, 2001), así como a la dialéctica entre instituciones antropológicas, la analogía con la tectónica de placas continuaría a través de tres tipos de choques entre plataformas continentales que habrían ayudado a conformarlas política e históricamente. Habría, en primer lugar, choques convergentes cuando dos plataformas continentales se han constituido mediante el choque frontal entre ambas, por ejemplo un choque frontal entre Imperios en el que uno se hunde respecto al otro que lo cambia elevándolo. En segundo lugar, encontraríamos los choques divergentes cuando dos plataformas continentales se separan, provocando que nuevos materiales institucionales o nuevas sociedades políticas emerjan. Por último, encontraríamos los choques transformantes cuando los Estados en dialéctica se "deslizan" institucional y políticamente unos con otros provocando todo tipo de cambios, por ejemplo mediante el imperialismo o el comercio.

La sistematización de nuestra teoría de las plataformas continentales descrita obliga a un "cierre geopolítico y antropológico-cultural" de las mismas. Para ello, en su momento propusimos siete características (Armesilla, 2014a) que permitirían cerrar positivamente cada plataforma continental de escala efectivamente histórico-universal, lo que no supone un "menosprecio" a otras formas de unidades geopolíticas (otros Estados, incluso con pasado imperialista o no, u otras unidades supraestatales), sino simplemente ver cuáles a nuestro juicio son las grandes unidades humanas en nuestro planeta. Estas siete características serían:

a) Lengua mayoritaria común, hablada por más de 200 millones de personas y entre las diez lenguas más habladas del planeta.

b) Religión mayoritaria común, con más de un $70 \%$ de la población siguiendo las típicas ceremonias e instituciones religiosas en la práctica totalidad de las sociedades políticas que conformarían cada plataforma continental, teniendo esas religiones, o confesiones religiosas, más de 200 millones de seguidores a escala mundial.

c) Pasado imperial común, entendiendo como Imperio a un Estado capaz de poner a su servicio a otros Estados o sociedades humanas hasta el punto de incorporarlos a su territorio, a una escala claramente intercontinental en la conformación de cada una de las sociedades políticas que conforman cada plataforma continental.

d) Tener una extensión conjunta de más de diez millones de kilómetros cuadrados. 
e) Un sistema político mayoritariamente común en el pasado y en el presente, aceptando cambios de sistema político a nivel mayoritario común, en cada una de las unidades políticas que conformarían cada plataforma continental.

f) Una población mayor de 300 millones de habitantes en cada plataforma continental.

g) Que al menos dos Estados inmersos en cada plataforma continental tengan fronteras terrestres comunes.

Según todo lo dicho anteriormente, admitiríamos y afirmaríamos la existencia de hasta cinco grandes plataformas continentales: la anglosajona, la eslava, la islámica, la asiática y la iberoamericana. Todas ellas tienen grandes potencias económicas y políticas en su seno o a grandes naciones emergentes: la anglosajona al Reino Unido, Canadá, Australia, Nueva Zelanda, Suráfrica (en los BRICS), etc.; la eslava a Polonia, Bielorrusia, Rumanía, etc.; la islámica a Arabia Saudita, Irán, Egipto, Argelia, Indonesia, Marruecos, etc.; la asiática a Corea del Norte, Vietnam, etc.; la hispánica a Brasil (en los BRICS), México (en la OCDE), España (en la UE), Argentina, Chile, Venezuela, Colombia, etc. Pero solo en tres de ellas hay actuales superpotencias mundiales, precisamente las que capitanean la construcción de las organizaciones supraestatales BRICS y ATCI. En la plataforma eslava, evidentemente a Rusia. En la plataforma asiática, a China. Y en la plataforma anglosajona, a los Estados Unidos de América. Es a través de estas tres grandes superpotencias militares, industriales, poblacionales, culturales y políticas como, a nuestro juicio, tanto la dialéctica ATCI Vs. BRICS, como en general la dialéctica de clases y de Estados y la dialéctica de plataformas continentales antes descritas se articularán en este siglo XXI. Pues solo Estados Unidos, Rusia y China tienen capacidad para reorganizar la apropiación territorial de otros Estados según sus intereses. El conflicto ucraniano entre la UEEEUU y Rusia sería un reciente ejemplo de ello, así como la partición de Sudán en dos con una república islámica al norte y otra cristiana al sur, etc. Solo estas tres grandes superpotencias universales tienen capacidad para comprar y vender deuda externa de otras potencias a escala geoestratégica universal tanto convergente, como divergente y transformante, especialmente EEUU y China (la República Popular China es, hoy día, el mayor tenedor de deuda exterior estadounidense), y solo estas tres superpotencias tienen capacidad para imponer sanciones comerciales a otros Estados en todos los continentes, y con efectos nocivos para la economía de los Estados sancionados. El bloqueo histórico de EEUU a Cuba o las sanciones rusas a los productos alimenticios de la UE son ejemplos de ello.

Estos tres grandes imperios universales, además, son los únicos con una capacidad armamentística suficiente como para ser clasificados como "superpotencias nucleares", aunque no hay datos homologados claros acerca de la fuerza nuclear china, pues no se sabe si es la cuarta potencia nuclear del Mundo tras Francia o si ya es la tercera (Fiódorov, 2012). China tiene más de 250 cabezas nucleares desplegadas, EEUU 8000 y Rusia 16000, heredadas todas de la Unión Soviética (todas según datos del Tratado de No Proliferación de Armas Nucleares firmado en 1968). Tras la disolución de la URSS en 1991, la Federación Rusa consiguió que EEUU y Francia apoyaran, según aprobación del Consejo de Seguridad de las Naciones Unidas integrado por estos tres 
Estados más China y el Reino Unido (todos ellos integrantes del bando vencedor en la Segunda Guerra Mundial), la transferencia en exclusiva de todo el arsenal nuclear desperdigado en el resto de repúblicas exsoviéticas a la actual Rusia.

\section{Conclusiones. Dialécticas políticas y determinismo causal histórico}

La previsible confrontación dialéctica entre la ATCI y los BRICS en este siglo XXI tendrá consecuencias sobre la geopolítica y las relaciones internacionales en el futuro inmediato derivadas, tanto del momento de su conformación efectiva, como de las líneas históricas, recientes y antiguas, que nos llevan a este momento histórico. Rusia y EEUU siguen ejerciendo un papel primordial en el orden internacional, como ya ocurrió en el siglo anterior. $Y$ en el caso de EEUU, este papel sigue reproduciendo esquemas de comportamiento como potencia geopolítica anteriores, profundizando en lo ya hecho. Pues a la firma del ATCI hay que sumar la del ATCE, redactado el 5 de octubre de 2015 y ratificado 4 de febrero de 2016, y que incluye como miembros a EEUU, México, Perú, Chile y Canadá en América, Brunei, Japón, Malasia, Vietnam y Singapur en Asia, y Australia y Nueva Zelanda en Oceanía. El ATCE es complementario del TTIP, y ya existen países que han anunciado su interés en entrar en dicho acuerdo, como Costa Rica, Colombia, India, Bangla Desh, Tailandia, Laos, Camboya, Corea del Sur, Taiwán, Filipinas e Indonesia.

Más allá de todo lo dicho, y como prospectiva de futuro, entendemos que la dialéctica ATCI vs. BRICS en este siglo XXI será ante todo, una reformulación de tres tradicionales dialécticas pretéritas cuyas líneas históricas determinan causalmente las dialécticas del presente y, presumiblemente, las del inmediato porvenir:

a) La dialéctica de clases y de Estados como motor de la Historia desde coordenadas de una concepción materialista de la vida política y de la conformación de las sociedades políticas, en tanto que la ATCI y los BRICS condicionarán en sentido dialéctico, y mixto, las relaciones de producción y laborales de sus sociedades integrantes y de otras.

b) La dialéctica de Imperios universales se da través da la anterior. Ya en la plataforma anglosajona a comienzos del siglo XX el Imperio Británico, por boca de Halford Mackinder, expresó sus intereses geoestratégicos universales. Mackinder publicó en 1904 su artículo El pivote geográfico de la Historia ([1904] 2010). Ahí señaló la importancia que la zona geográfica que comprendería Siberia y Asia Central, pertenecientes en aquel momento al Imperio Ruso, tiene a escala universal. Por sus recursos naturales, su población y su innacesibilidad por mar salvo el Océano Glacial Ártico, unido a una pérdida efectiva en ciernes del poderío del Imperio Británico respecto a un auge del poderío militar, industrial y económico ruso, harían que el interés británico por este área, llamada área pivote, adquiriese una importancia fundamental. Para Mackinder, quien dominara esta área pivote dominaría el Mundo. Al pensar, desde las coordenadas del imperialismo británico, que el reparto colonial de la Tierra había finalizado y que era menester derivar a otras formas de dominación mundial, Mackinder argumentó que el dominio de las tierras que rodean el área pivote, esto es, la media luna creciente entre Europa 
del Este e Indochina, pasando por Oriente Medio y la India, más la presencia en el área marítima que rodea la gran Isla euroasiática, también aseguraría la dominación mundial (Cairo, 2010). Con Nicholas Spykman (1942) el área pivote comienza a dejar de ser el área de dominación mundial para serlo ahora el cinturón exterior, la media luna creciente antes mencionada. Para Spykman, el dominio de esta media luna ayudaría al control de los mares y a cercar el área pivote mackinderiana. Esta estrategia es la continuada a día de hoy por los Estados Unidos de América en su enfrentamiento primero con la Unión Soviética y ahora con la Rusia de Putin-Medvedev, aunque existen ya teorías alternativas con otras áreas pivote de dominación mundial, por ejemplo la teoría del "nuevo pivote global" (Martín, 2010) o la de los Balcanes euroasiáticos, básicamente Asia Central en exclusiva (Brzezinski, 1998). No obstante, la complementariedad ATCI-ATCE reproduce, a nuestro juicio, el cerco sobre el área pivote euroasiática realizado sobre la media luna creciente que va desde el Báltico al Pacífico.

c) En la Historia se daría, además, un dialéctica de Imperios en base al tipo de organización comercial y antropológica que se da en los territorios que dominan y la continuidad de las rutas comerciales entre dichas organizaciones en base a si sus dominios son tierras de navegación o tierras emergidas. Habría una dialéctica entre potencias políticas talasocráticas, es decir, aquellos imperios cuya base de dominación imperial reside en el control del comercio y las instituciones antropológico-culturales en intercambio y expansión a través de mares y océanos, sin desdeñar una hipotética gran extensión territorial, y potencias políticas telurocráticas, que son aquellos imperios cuya base de dominación imperial reside en el control del comercio y las instituciones antropológico-culturales en intercambio y expansión a través sobre todo de vastas y extensas tierras emergidas, sin desdeñar la posibilidad de tener una gran flota marítima. El gran imperio talasocrático del siglo XX y del XXI por ahora son los Estados Unidos de América, mientras que Rusia y China serían más bien imperios telurocráticos. La dialéctica entre estos tres grandes imperios, conectada con las dos mencionadas anteriormente, se entreteje con la dialéctica a punto de producirse entre la ATCI, en tanto se vaya conformando y se cierre, y los BRICS. Una dialéctica causalmente determinada por múltiples líneas históricas que no dejan de ejercer, desde el pretérito, su influencia sobre nuestras vidas, frente a cuya determinación ejercemos nuestra libertad para obrar. Frente a estas dialécticas tratan de ejercer también su libertad de acción nuestras sociedades políticas, que también influirán en los choques convergentes, divergentes y transformantes que entretejen las sociedades políticas que, a través de la dialéctica de clases y de Estados, pertenezcan a diversas organizaciones supraestatales o postestatales. Y en donde, históricamente, las talasocracias han sido hegemónicas prácticamente en cada época histórica. A pesar de su extensión considerable sobre tierras emergidas, la complementariedad ATCI-ATCE permite, a EEUU ejercer de imperio talasocrático una vez más.

La dialéctica ATCI vs. BRICS, sería una reformulación de diversas dialécticas históricas derivadas desde hace siglos, que no pueden obviarse. Y estas dialécticas políticas e históricas influyen en otra serie de movimientos geopolíticos y geoeconómicos 
contemporáneos en el tiempo al ATCI y a los BRICS. No ya solo por las obvias interdependencias que la conformación de estos dos grandes bloques sufren, y que se derivan de interdependencias también anteriores en otras dialécticas históricas. El largo periodo histórico de la Modernidad en que estamos inmersos, iniciado en el Renacimiento, con el surgimiento de los primeros Estados-nación y la ampliación del comercio mundial con el Descubrimiento de América en 1492, culmina en muchos aspectos con la actual globalización económica, la cual no puede entenderse sin los procesos históricos enumerados en este texto.

Hemos querido resaltar la importancia que, en toda la Historia, ha tenido la forma en que se han relacionado las instituciones de los Estados a nivel político, económico y antropológico-cultural, en un enfoque, estimamos, compatible con otros (Agnew, 2005). Pues la hegemonía del poder mundial actual, que depende tanto de la gestión sobre los recursos estratégicos nacionales y globales como de las fluctuaciones, a veces turbulentas, de la historia económica de las naciones modernas (Arrighi y Silver, 1994), ahora en el siglo XXI depende de la conformación de plataformas transestatales, intercontinentales, donde varias potencias se apoyan entre sí, aunque haya una superpotencia hegemónica en cada plataforma continental. Las ligas políticas de Estados no son nuevas, y en todas ellas el equilibrio de poder y de intereses es siempre problemático. Pero, al mismo tiempo, ninguna alianza transestatal surge de la nada, y en todos los casos pueden rastrearse antecedentes pretéritos que, en gran medida, influirán en el devenir de las nuevas alianzas a conformar.

\section{Abreviaturas}

$\begin{array}{ll}\text { ATCE } & \text { Acuerdo Transpacífico de Cooperación Económica } \\ \text { ATCI } & \text { Asociación Transatlántica para el Comercio y la Investigación } \\ \text { ASEAN } & \text { Asociación de Naciones del Sudeste Asiático } \\ \text { BRIC } & \text { Brasil, Rusia, India, China } \\ \text { BRICS } & \text { Brasil, Rusia, India, China, Suráfrica } \\ \text { CECA } & \text { Comunidad Europea del Carbón y del Acero } \\ \text { CED } & \text { Comunidad Europea de Defensa } \\ \text { CEE } & \text { Comunidad Económica Europea } \\ \text { ECU } & \text { Unidad Monetaria Europea (European Currency Unit) } \\ \text { EEUU } & \text { Estados Unidos de América } \\ \text { EURATOM } & \text { Comunidad Europea de Energía Atómica } \\ \text { G-7 } & \text { Los siete países más industrializados del Mundo (sin Rusia) } \\ \text { G-8 } & \text { Los ocho países más industrializados del Mundo } \\ \text { G-20 } & \text { Los veinte países más industrializados del Mundo } \\ \text { G-77 } & \text { Países no alineados (fundadores) }\end{array}$


G-133 Países no alineados hoy

OTAN Organización del Tratado del Atlántico Norte

OCDE Organización para la Cooperación y el Desarrollo Económico

PIB Producto Interior Bruto

TUE Tratado de la Unión Europea (Mastrique)

UE Unión Europea

URSS Unión de Repúblicas Socialistas Soviéticas

\section{Bibliografía}

Agnew, J. A. (2005): Hegemony: the new shape of Global Power, Philadelphia, Temple University Press.

Arrighi, B. y B. J. Silver, (1994): El largo siglo XX, Madrid, Akal.

Alcázar González J. y M. Montejo López (2014): El Tratado de Libre Comercio (TTIP) entre la Unión Europea y Estados Unidos. Disponible en:

http://www.frentecivicosomosmayoria.es/wp-content/uploads/2014/06/FCSM.-

TRATADO-DE-LIBRE-COMERCIO-ENTRE-UE-Y-EE.UU_..pdf.

Armesilla, S. (2014a): "Las plataformas continentales: una división geopolítica del Mundo desde las coordenadas del materialismo filosófico de Gustavo Bueno", Nómadas, 41 (I). Disponible en:

http://www.theoria.eu/nomadas/41/sjarmesilla_3.pdf.

DOI: http://dx.doi.org/10.5209/rev_NOMA.2014.47994

Armesilla, S. (2014b): "Apéndice a- artículo "Las plataformas continentales": la analogía de la formación de las plataformas con la tectónica de placas", Nómadas, 41 (I). Disponible en:

http://www.theoria.eu/nomadas/41/sjarmesilla_4.pdf.

DOI: http://dx.doi.org/10.5209/rev_NOMA.2014.47994

Beneyto Pérez, J. M., G. Pérez Sánchez y R. Martín de la Guardia, ed. (2005): Europa y Estados Unidos: una Historia de la relación atlántica en los últimos cien años, Madrid, Biblioteca Nueva.

Brzezinski, Z. (1998): El gran tablero mundial: la supremacía estadounidense y sus imperativos geoestratégicos, Barcelona, Paidós Ibérica.

Bueno, G. (1991): Primer ensayo sobre las categorías de las "ciencias politicas", Logroño, Biblioteca Riojana.

Bueno, G. (1992): Teoría del cierre categorial, Oviedo, Pentalfa.

Bueno, G. (2001): "Dialéctica de clases y dialéctica de Estados", El Basilisco, 30 (2), pp. 83-90.

Bueno, G. (2005): "Ensayo de una teoría antropológica de las instituciones”, El Basilisco, 37 (2): pp. 3-52.

Bureau of Public Affairs (2013): Los Estados Unidos y la Unión Europea: construir a partir de nuestra Asociación Económica y Estratégica. Disponible en:

http://ec.europa.eu/spain/pdf/ttip/usa-contruir-asociacion-estrategica.pdf. 
Cairo, H. (2010): "El pivote geográfico en la Historia", el surgimiento de la geopolítica clásica y la persistencia de una interpretación telúrica de la política global, Geopolítica(s). 2 (1), pp. 321-331.

Center for Economic Policy Research (2013): Final report: high level working group on jobs and growth. Disponible en: http://trade.ec.europa.eu/doclib/docs/2013/february/tradoc_150519.pdf.

Comisión Europea -Representación en España- (2014): Sobre la UE: Tratado de Libre Comercio entre la UE y USA. Disponible en: http://ec.europa.eu/spain/sobre-la-ue/ttip/espana_es.htm.

Fiódorov, V. (2012): "Por su potencia nuclear, China ya no es un tigre de papel”, La voz de Rusia, 4 de octubre. Disponible en:

http://sp.ria.ru/spanish_ruvr_ru/2012_10_04/china-armas-nucleares-potencialeeuu-rusia/ .

García Matías, B. (2014): “`Menos Estado y más sociedad civil!’: Una crítica al primado de la dialéctica de comunidades sobre la dialéctica de Estados", Nómadas, 41 (I). Disponible en:

http://www.theoria.eu/nomadas/41/bettinagmatias_2.pdf.

DOI: http://dx.doi.org/10.5209/rev_NOMA.2014. $\overline{4} 8001$

García Sierra, P. (2000): Diccionario filosófico, Oviedo, Pentalfa.

Guerrero, D. (1989): Una aproximación polémica a la teoría marxista de las crisis económicas. Disponible en:

http://old.kaosenlared.net/media/12/12386_0_Una_aproximacion_polemica.pdf.

Hallstein, W. y H. Bräker (1975): “Comunidad Económica Europea”, en Kerning, C. D. ed., Marxismo y democracia: enciclopedia de conceptos básicos, Madrid, Editorial Rioduero.

Kant, I. (1983): Perpetual peace and other essays, Indianápolis, Hackett.

Ladines, J. C. (2013): "Potencias emergentes y pragmatismo regional: el ascenso de los BRIC en el turbulento panorama internacional", Tiempo de Opinión, 6, pp. 46-53.

López Muñoz, I. (1979): "La URSS, contra el ingreso de España en la CEE”, El País, 1 de marzo. Disponible en:

http://elpais.com/diario/1979/03/01/internacional/289090810_850215.html.

Mackinder, H. (2010): "El pivote geográfico en la Historia”, Geopolítica(s), 2(1), pp. 301-319.

Majfud, J. (2009): “BRIC, la comunidad fantasma”, Pagina12, 17 de junio. Disponible en:

http://www.pagina12.com.ar/diario/contratapa/13-126757-2009-06-17.html.

Martín, X. (2010): Moyen orient, novueau pivot global? Disponible en: http://www.xaviermartin.fr/index.php?post/2010/01/04/MOYEN-ORIENT\%2CNOUVEAU-PIVOT-GLOBAL.

Martín de la Guardia, R. y G. Pérez Sánchez (2005): La URSS contra las Comunidades Europeas: la percepción soviética del mercado común (1957-1962), Valladolid, Estudios y Documentos.

O’ Neill, J. (2001): "Building better global economic BRICs”, Global Economics, 66. 
Schiff, P. (2014): "La deuda no es ninguna salvación", Libremercado, 17 de septiembre. Disponible en: http://www.libremercado.com/2014-09-17/peter-schiff-la-deuda-no-es-ningunasalvacion-73453/.

Spykman, N. (1942): America's strategy in world politics, Nueva York, Harcourt, Brace \& Worlds.

Todd, E. (2003): Después del Imperio: ensayo sobre la descomposición del sistema estadounidense, Madrid, Foca.

VV.AA. (1957): "Informe del Instituto de Economía y Relaciones Internacionales de la Academia de Ciencias de la URSS", El comunista. 9, pp. 88-102.

Wilson, D. y R. Purushothaman (2003): "Dreaming with BRICs: the path to 2050", Global Economics, 99. 